\title{
Metode Desain VDI 2221 Untuk Merancang SKID MPFM SINGLE LINE
}

\author{
Rudi Kurniawan Arief \\ Prodi Teknik Mesin, Fakultas Teknik, Universitas Muhammadiyah Sumatera Barat, Bukittinggi \\ email: rudi.arief@gmail.com
}

\begin{abstract}
MPFM (Multi Phase Flow Meter) is an on field tools to measure the flow and compotition of crude oil during mud logging process. This tool unit operated beside logging well area so the result can be obtained directly on site. Because of remote access in mining location, a small and lighter measuring unit tools required in order to have easy transportation, storaging and installing of the unit. The MPFM Single line unit then developed to answer this problems VDI 2221 design methode is using to design this new unit where the primary data gathered from litercy study, interview with the company's management staffs and operators. This design methode obtain 4 product variations where 1st Varian was choosed as the best design.
\end{abstract}

Keywords: MPFM, VDI 2221, Design Methode, Mechanical Design.

\section{PENDAHULUAN}

MPFM (Multi Phase Flow Meter) merupakan suatu alat yang digunakan untuk mengukur aliran dan komposisi dari minyak dan gas bumi yang tercampur dalam lumpur galian (mud logging) yang berisi berbagai jenis material tanpa harus melakukan proses pemisahan (fluid separation) terlebih dahulu. Hasil pengukuran yang presisi dan berkualitas tinggi dihasilkan oleh detektor nuklir dengan sumber barium-133 dan smart detector yang sudah dirancang khusus sehingga tidak membahayakan para pekerja di lapangan. $M P F M$ diaplikasikan langsung di lapangan dengan posisi yang dekat dengan logging well dan hasilnya bisa langsung diperoleh di tempat.

Unit generasi pertama dipersiapkan untuk bisa digunakan pada kondisi sumur yang menggunakan pipa kecil 2" dan pipa besar 4". Dimensi unit cukup besar karena terdapat dua line dalam satu skid. Besarnya ukuran unit ini cukup menyulitkan dalam hal penyimpanan, transportasi dan penyusunan pada saat proses produksi dilakukan sehingga menjadi terlalu rumit dan terlalu banyak memakan biaya.

Pesatnya kemajuan teknologi dan semakin ketatnya persaingan antar perusahaan dalam bisnis minyak bumi dan gas alam menyebabkan perusahaan harus berusaha semaksimal mungkin untuk menjaga dan memajukan bisnis mereka. Peningkatan teknologi yang diawali oleh proses desain harus mampu mengakomodasi semua perubahan teknologi, lingkungan, kebiasaan operator, ergonomi dan penyederhanaan proses yang akan membawa suatu efesiensi proses sehingga berdampak juga terhadap efisiensi pengeluaran tanpa mengorbankan fungsi teknis, kepresisian dan kehandalan dari alat yang didesain tersebut.

\section{METODE PENELITIAN}

Kesempurnaan produk yang dibuat sangat ditentukan oleh ketepatgunaan dan efektifitas dari prosesnya yang dimulai dari proses desain itu sendiri. Berbagai kebutuhan dan aspek dalam desain harus disesuaikan terhadap kondisi perusahaan, situasi pasar, kenyamanan pengguna dan perkembangan teknologi. Semua kebutuhan di atas dapat diakomodir dengan penggunaan metode VDI 2221 ini.

Ukuran yang besar pada unit yang sudah ada menimbulkan beberapa permasalahan tersendiri antara lain adalah sempitnya lokasi penambangan terutama di lepas pantai di mana semua unit dari berbagai fungsi dan berbagai services company harus disusun pada lokasi yang sangat terbatas sehingga dimensi unit bisa menjadi suatu permasalahan. Ukuran yang besar berarti unit yang berat, sehingga dibutuhkan peralatan khusus untuk proses pemindahan serta tempat yang cukup luas untuk penyimpanan. Berdasarkan masukan dari operational team di lapangan, dari dua line yang terdapat pada skid generasi pertama ini ternyata hanya line 4 " yang sering dipergunakan. 
Untuk mengatasi permasalahan tersebut maka dirancang skid generasi kedua dengan hanya menempatkan satu line saja yaitu line 4" sehingga bisa diperoleh ukuran yang lebih kecil dan mempunyai bobot lebih ringan. Metode perancangan VDI2221 diterapkan pada penelitian ini agar didapatkan hasil rancangan terbaik.

Langkah kerja yang terdapat dalam metode VDI 2221 mempertepat dan memperjelas tugas, menentukan fungsi struktur, mencari prinsip solusi beserta strukturnya, menguraikan varian yang dapat direalisasikan, memberikan bentuk pada model serta merinci pembuatan dan penggunaannya.

Di dalam penelitian ini penulis akan menjelaskan dan menjabarkan penerapan metode VDI 2221 dalam desain alat MPFM Single Phase Unit.

Bebrapa langkah pengumpulan dan pengolahan data yang dilakukan dalam penelitian ini antara lain :

1. Survei lapangan, yaitu melihat secara langsung maupun tidak langsung permasalahan yang terjadi di lapangan.

2. Studi pustaka, yaitu mencari data dan informasi dari buku-buku referensi, literatur, jurnal dan penelusuran internet.

3. Diskusi, yaitu wawancara dan berdiskusi dengan pihak-pihak yang berkompeten untuk mengumpulkan data primer dan sekunder dalam penyusunan daftar kehendak.

\section{HASIL DAN PEMBAHASAN}

Perancangan Skid MPFM single line ini merupakan pengembangan dan penyederhanaan dari sistem MPFM double line yang sudah ada pada PT. WN untuk mengoptimalkan kinerja dan penggunaannya di lapangan sehingga lebih sesuai dengan kondisi kerja dan keinginan customer. Adapun langkah-langkah yang telah penulis tempuh dalam perancangan antara lain :

a. Pengumpulan data melalui wawancara dan pengamatan di lapangan.

b. Analisa dan pengolahan data berdasarkan referensi dari literatur, buku, serta beberapa pendekatan asumsi. c. Menarik kesimpulan dan memberikan saran-saran untuk pengembangan lebih lanjut.

\section{Penyusunan Daftar Kehendak}

Daftar kehendak merupakan beberapa hal yang dikumpulkan untuk melakukan perancangan suatu alat agar dapat menghasilkan alat yang benar-benar bisa menjawab permasalahan yang ada. Adapun sifatnya masih umun dan susunannya belum teratur.

Tahap pertama adalah pengumpulan ide-ide yang masih bersifat umum tanpa batasan-batasan tertentu.

Adapun ide-ide untuk perancangan skid MPFM single line tersebut dikumpulkan dalam suatu daftar kehendak sebagai berikut :

1. Berat $<800 \mathrm{~kg}$.

2. Dimensi < 1000x1000x1500mm.

3. Satu line MPFM saja.

4. Bisa diangkat dari atas

5. Bisa diangkat dari bawah.

6. Material yang sudah disertifikasi.

7. Skid harus cocok dengan line yang didesain di Perancis.

8. Bisa menggunakan Connector API \& Weco.

9. Sesuai sertifikasi DNV 27-1.

10. Perakitan mudah

11. Perakitan line ke skid mudah

12. Manufakturing tidak rumit.

13. Bisa menyimpan $20 \mathrm{~m}$ kabel instrumen.

14. Aman dari benturan.

15. Mudah dibongkar.

16. Mudah dipindahkan.

17. Ada cover pelindung.

18. Cover pelindung mudah dibongkarpasang.

19. Bisa dipindah dengan mesin.

20. Bisa dipindah secara manual.

21. Mampu menahan line dari getaran.

22. Ada sesuatu untuk menyangga berat dari connector.

23. Penyangga bisa dibongkar-pasang dengan mudah dan aman.

24. Penyangga bisa dipindah posisikan.

25. Penyangga line harus kuat tapi 
mudah di-adjust.

26. Sensor-sensor harus terlindung dari benturan.

Semua data-data yang berkaitan dengan tugas yang bertujuan untuk pemecahan masalah serta sifat-sifat yang harus dimiliki didefinisikan secara lengkap dan jelas menjadi suatu daftar spesifikasi.

\section{Spesifikasi Skid Single Line MPFM}

Berikut adalah tabel spesifikasi skid single line MPFM yang telah disaring dan dikelompokkan dari ide-ide yang ada pada daftar kehendak.

Tabel 1. Daftar spesifikasi Skid single line

\begin{tabular}{|c|c|c|c|}
\hline & & $D$ & \\
\hline No & Faktor & $\begin{array}{l}\mathrm{D} / \\
\mathrm{W}\end{array}$ & Persyaratan \\
\hline 1 & \multirow{2}{*}{ Energi } & $\mathrm{D}$ & $\begin{array}{l}\text { Mampu bekerja } \\
\text { dengan normal } \\
\text { pada suhu } 70^{\circ} \mathrm{C} \sim \\
-20^{\circ} \mathrm{C} \text {. }\end{array}$ \\
\hline 2 & & $\mathrm{D}$ & $\begin{array}{l}\text { Komponen } \\
\text { pengencang } \\
\text { mampu menahan } \\
\text { beban sampai } \\
\text { 500kg. }\end{array}$ \\
\hline 3 & Gaya & $\mathrm{W}$ & Berat $<800 \mathrm{~kg}$. \\
\hline 4 & Geometri & W & $\begin{array}{l}\text { Dimensi < } \\
\text { 1000x 1000x } 1500 \\
\mathrm{~mm} .\end{array}$ \\
\hline 5 & \multirow{5}{*}{ Produksi } & $\mathrm{D}$ & $\begin{array}{l}\text { Untuk satu line } \\
\text { MPFM saja. }\end{array}$ \\
\hline 6 & & W & $\begin{array}{l}\text { Bisa menyimpan } \\
\text { kabel instrumen \& } \\
\text { tenaga sepanjang } \\
\text { 20m dengan aman. }\end{array}$ \\
\hline 7 & & W & $\begin{array}{l}\text { Menggunakan } \\
\text { proses permesinan } \\
\text { standar. }\end{array}$ \\
\hline 8 & & $\mathrm{~W}$ & $\begin{array}{l}\text { Produksi dengan } \\
\text { peralatan yang } \\
\text { tersedia (inhouse). }\end{array}$ \\
\hline 9 & & $\mathrm{D}$ & $\begin{array}{l}\text { Proses } \\
\text { manufakturing }\end{array}$ \\
\hline
\end{tabular}

\begin{tabular}{|c|c|c|c|}
\hline & & & $\begin{array}{l}\text { harus mengikuti } \\
\text { standarisasi DNV. }\end{array}$ \\
\hline 10 & \multirow[t]{2}{*}{ Material } & $\mathrm{D}$ & $\begin{array}{l}\text { Menggunakan } \\
\text { material sesuai } \\
\text { standar DNV dan } \\
\text { ada sertifikat } \\
\text { properties dan } \\
\text { pengujiannya. }\end{array}$ \\
\hline 11 & & $\mathrm{D}$ & $\begin{array}{l}\text { Material ada } \\
\text { sertifikat } \\
\text { properties dan } \\
\text { pengujiannya. }\end{array}$ \\
\hline 12 & \multirow{3}{*}{$\begin{array}{c}\text { Transporta } \\
\text { si }\end{array}$} & $\mathrm{D}$ & $\begin{array}{l}\text { Skid dapat } \\
\text { diangkat dari atas } \\
\text { dan dari bawah. }\end{array}$ \\
\hline 13 & & W & $\begin{array}{l}\text { Ringan dan mudah } \\
\text { dipindah dengan } \\
\text { alat sederhana. }\end{array}$ \\
\hline 14 & & W & $\begin{array}{l}\text { Tidak memakan } \\
\text { banyak tempat. }\end{array}$ \\
\hline 15 & \multirow{3}{*}{ Perakitan } & $\mathrm{D}$ & $\begin{array}{l}\text { Harus sesuai } \\
\text { dengan line } \\
M P F M \text { dari } \\
\text { Perancis }\end{array}$ \\
\hline 16 & & $\mathrm{D}$ & $\begin{array}{l}\text { Connector API } \\
\text { dan Weco harus } \\
\text { dapat digunakan } \\
\text { (tergantung } \\
\text { permintaan } \\
\text { customer). }\end{array}$ \\
\hline 17 & & W & $\begin{array}{l}\text { Line MPFM bisa } \\
\text { dirakit dengan } \\
\text { mudah ke dalam } \\
\text { skid. }\end{array}$ \\
\hline 18 & \multirow{3}{*}{ Safety } & $\mathrm{D}$ & $\begin{array}{l}\text { Aman dari } \\
\text { benturan. }\end{array}$ \\
\hline 19 & & $\mathrm{D}$ & $\begin{array}{l}\text { Sensor-sensor } \\
\text { harus terlindung. }\end{array}$ \\
\hline 20 & & W & $\begin{array}{l}\text { Ada cover } \\
\text { pelindung. }\end{array}$ \\
\hline 21 & Ergonomi & $\mathrm{D}$ & $\begin{array}{l}\text { Penyangga } \\
\text { connector dan } \\
\text { connector itu }\end{array}$ \\
\hline
\end{tabular}

Fakultas Teknik UMSB
ISSN 2599-2081

EISSN 2599-2090 


\begin{tabular}{|c|c|c|c|}
\hline & & & $\begin{array}{l}\text { sendiri bisa } \\
\text { dipindah posisikan } \\
\text { dengan mudah. }\end{array}$ \\
\hline 22 & & $\mathrm{D}$ & $\begin{array}{l}\text { Connector API } \\
\text { dan Weco bisa } \\
\text { dipindah posisikan } \\
\text { tanpa harus } \\
\text { membongkar line } \\
\text { atau membuka } \\
\text { skid. }\end{array}$ \\
\hline 23 & & $\mathrm{D}$ & $\begin{array}{l}\text { Electric box di } \\
\text { dalam skid bisa } \\
\text { diakses dengan } \\
\text { mudah. }\end{array}$ \\
\hline 24 & & D & Tahan karat. \\
\hline 25 & Perawatan & W & $\begin{array}{l}\text { Spare part mudah } \\
\text { didapat. }\end{array}$ \\
\hline 26 & Biaya & W & $\begin{array}{l}\text { Sebisa mungkin } \\
\text { meggunakan } \\
\text { material yang } \\
\text { tersedia di dalam } \\
\text { negeri. }\end{array}$ \\
\hline 27 & & W & $\begin{array}{l}\text { Proses produksi } \\
\text { inhouse sehingga } \\
\text { biaya produksi } \\
\text { bisa lebih rendah. }\end{array}$ \\
\hline
\end{tabular}

Keterangan :

D : Demand (tuntutan yang harus dipenuhi), adalah persyaratan yang mutlak untuk dipenuhi pada setiap kondisi perancangan, dengan kata lain apabila persyaratan ini tak terpenuhi maka perancangan dianggap gagal.

$\mathrm{W}$ : Wishes (keinginan) merupakan persyaratan yang diinginkan dan tidak bersifat mutlak, persyaratan ini boleh diabaikan apabila kondisinya tidak memungkinkan.

\section{A. Penentuan Struktur Fungsi}

\section{a. Fungsi Keseluruhan}

Fungsi ini digambarkan dalam diagram

blok yang menujukkan hubungan antara masukan dan keluaran yang berupa aliran dari energi, material dan sinyal.

Fungsi dari skid single line MPFM ini adalah untuk menyangga dan melindungi line MPFM beserta seluruh sensor-sensor dan peralatan elektronik lainnya.

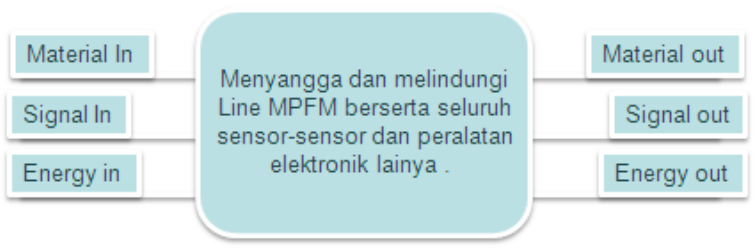

Gambar 1. Fungsi keseluruhan skid single line MPFM.

\section{b. Struktur Fungsi}

Struktur fungsi didefinisikan sebagai hubungan secara umum antara input dan output suatu sistem teknik yang akan mejalankan suatu tugas tertentu dari suatu subsistem yang telah ada maupun yang baru sehingga keduanya dapat diuraikan secara terpisah.

Struktur fungsi berdasarkan unsur utama dalam alat ini adalah sebagai berikut :

1. Primary structure.

Perlu dicari prinsip solusi agar didapatkan primary structure yang kuat, aman tapi mempunyai bobot yang relatif ringan dengan biaya yang tidak terlalu mahal.

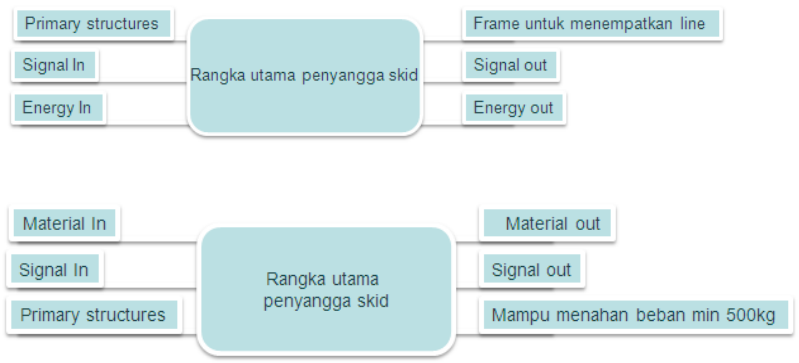

Gambar 2. Fungsi Primary Structure.

2. Pad eye.

Perlu dicari prisip solusi agar pad eye kuat mengangkat skid beserta isinya dengan aman dan mampu untuk tetap bekerja dengan normal pada suhu $70^{\circ} \mathrm{C}$ sampai $-20^{\circ} \mathrm{C}$. 


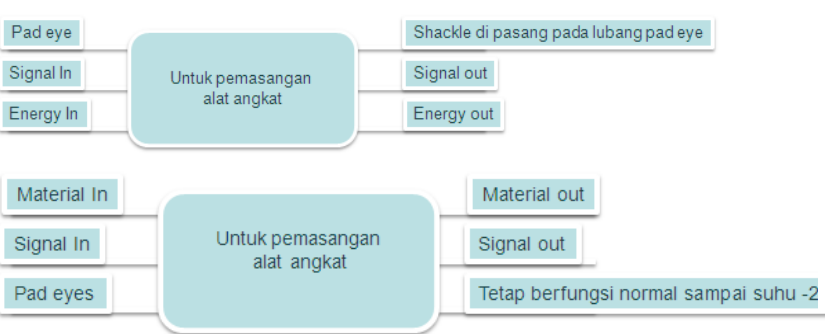

Gambar 3. Fungsi Pad eye.

3. Frame connector.

Perlu dicari prisip solusi agar upper frame dengan base frame dapat terhubung dengan aman tanpa mempersulit proses perakitan line MPFM ke dalam skid ini.

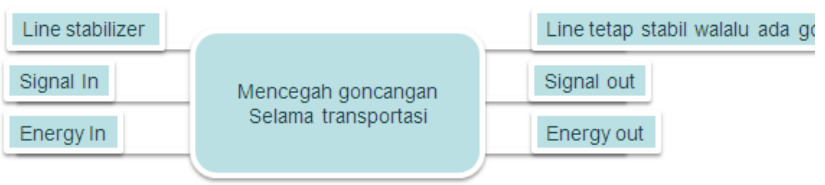

Gambar 4. Fungsi Frame connector.

4. Line stabilizer.

Perlu dicari prisip solusi agar line

MPFM yang berada di dalam skid

tidak mengalami guncangan yang

berarti selama transportasi.

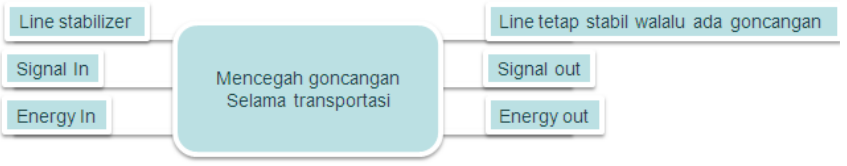

Gambar 5. Fungsi Line stabilizer.

5. Line support.

Perlu dicari prinsip solusi untuk menyangga line MPFM agar bisa berdiri dengan sempurna di dalam skid dan tidak mudah collapse tetapi tidak sulit pemasangannya.

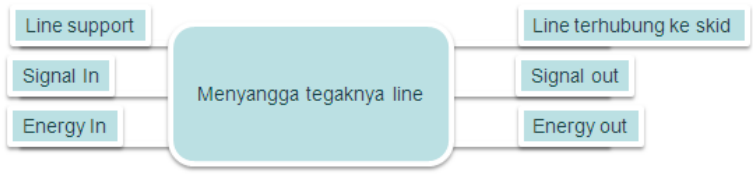

Gambar 6. Fungsi Line support.

6. Cover.

Perlu dicari prinsip solusi agar line

MPFM, sensor-sensor beserta peralatan elektronik yang ada di dalam skid tidak mudah terkena gangguan dari benda asing tanpa mengurangi kemudahan untuk mengaksesnya.

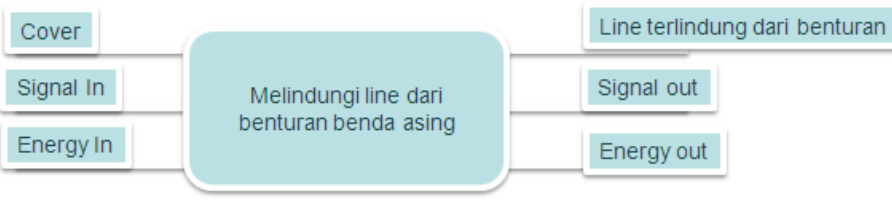

Gambar 7. Fungsi Cover.

7. Pengunci cover.

Perlu dicari prisip solusi untuk penguncian cover sehingga mudah dibongkar-pasang tanpa alat khusus tetapi tetap kuat dan tak mudah lepas.

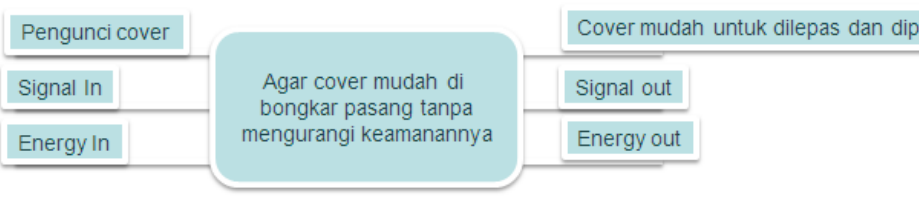

Gambar 8. Fungsi Pengunci cover.

8. Connector support.

Perlu dicari prisip solusi agar connector tidak membuat collapse unit single line MPFM ini tetapi bisa ditempatkan di posisi manapun.

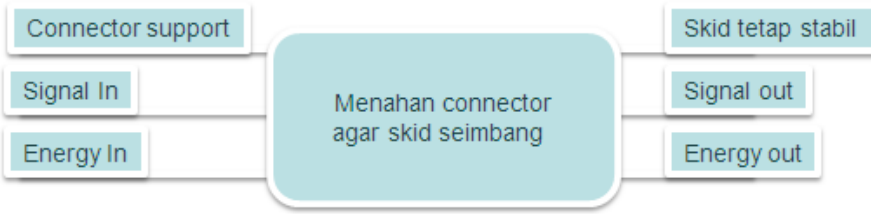

Gambar 9. Fungsi Connector support

9. Base frame.

Perlu dicari prinsip solusi agar base

frame mampu menahan beban dari

line MPFM, selain itu juga harus

berfungsi sebagai titik pengangkatan.

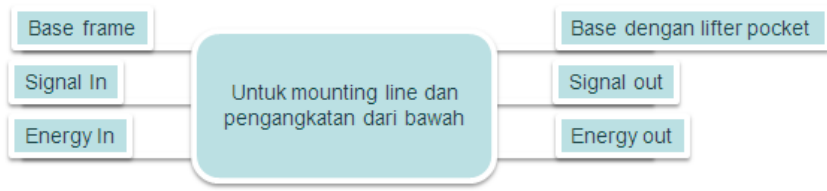

Gambar 10. Fungsi Base Frame.

10. Posisi connector.

Perlu dicari prinsip solusi agar connector dan support-nya bisa diposisikan ke arah manapun sesuai dengan kondisi di lapangan. 


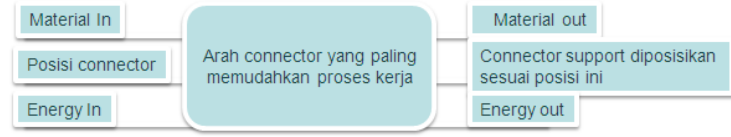

Gambar 11. Fungsi Posisi Connector.

11. Top frame.

Perlu dicari prinsip solusi agar top frame bisa melindungi frame, kokoh tetapi bobot tidak terlalu berat dan tidak mengganggu proses perakitan line ke dalam frame-nya.

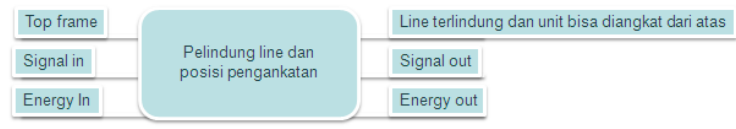

Gambar 12. Fungsi Top Frame.

12. Cable hanger.

Perlu dicari prinsip solusi agar kabel elektrik dan kabel data dapat disimpan dengan aman pada skid ini.

\begin{tabular}{|l|l|}
\hline Material In & \multicolumn{1}{|c|}{ Material out } \\
\hline Cabel hanger \\
\hline Energy In \\
\hline
\end{tabular}

Gambar 12. Fungsi Cable Hanger

Tabel 2. Prinsip Solusi

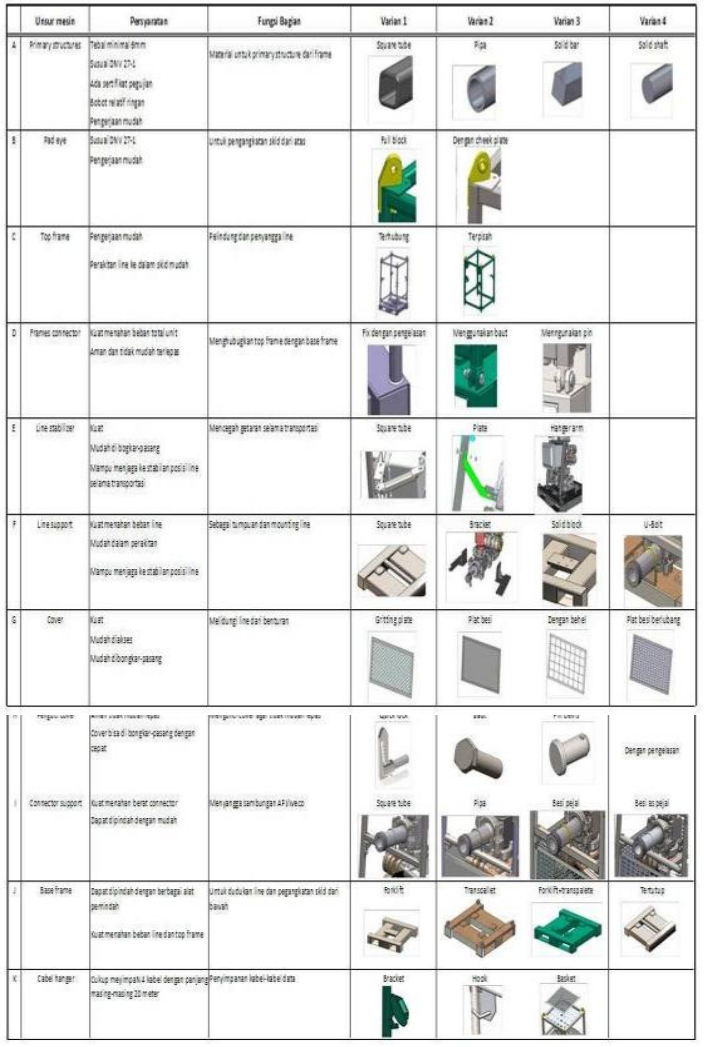

B. Mencari dan Memilih Prinsip Solusi untuk Subfungsi Utama

Setiap subfungsi dalam struktur fungsi di atas haruslah dicari prinsip solusinya dan akan diuraikan berdasarkan unsur-unsur yang telah disebutkan di atas.

Berikut adalah tabel prinsip solusi yang berisi beberapa alternatif komponen yang dapat digunakan pada rancangan ini.

\section{Memilih Variasi Kombinasi Terbaik}

Karena ada 4 macam kombinasi, maka harus dilakukan suatu seleksi agar perancangan akhir bisa benar-benar mendekati tuntutan desain. Pengkajian terhadap variasi-variasi yang sudah ada harus dilakukan agar bisa mendapatkan kombinasi terbaik yang disajikan dalam tabel pemilihan variasi struktur fungsi pada tabel berikut.

Tabel 3. Pemilihan Variasi Struktur Fungsi

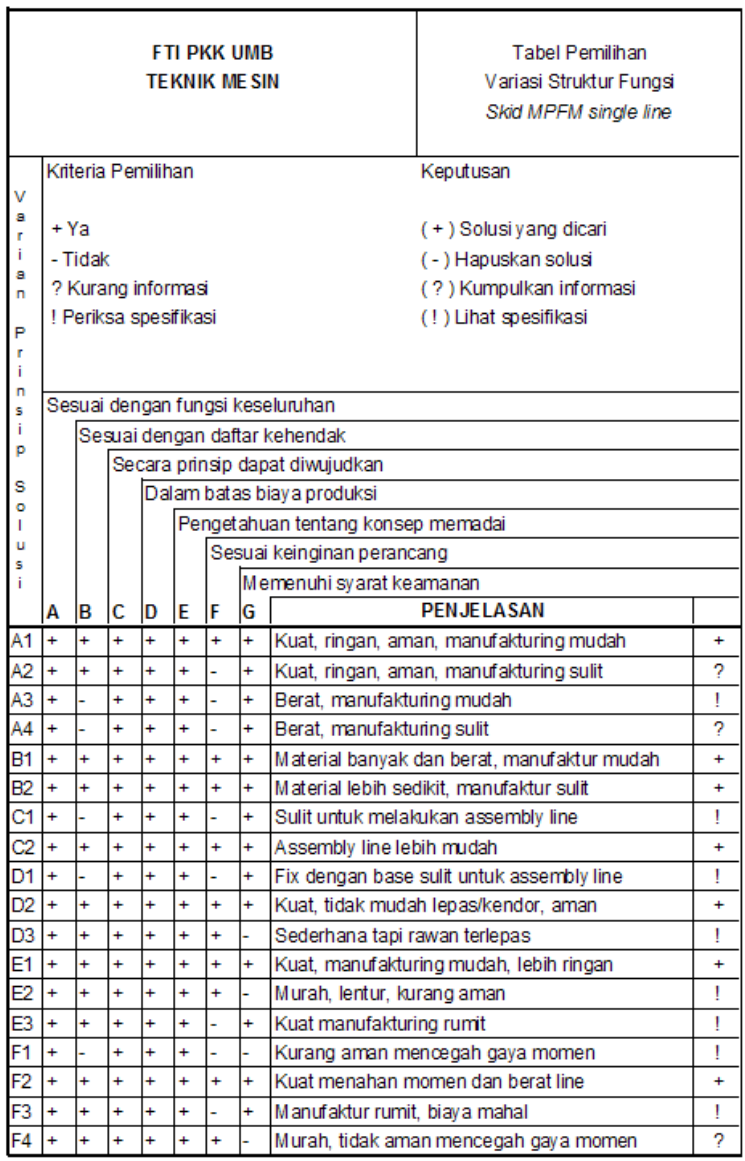


Vol. I No.2 Juni 2018

http://joernal.umsb.ac.id/index.php/RANGTEKNIKJOURNAL

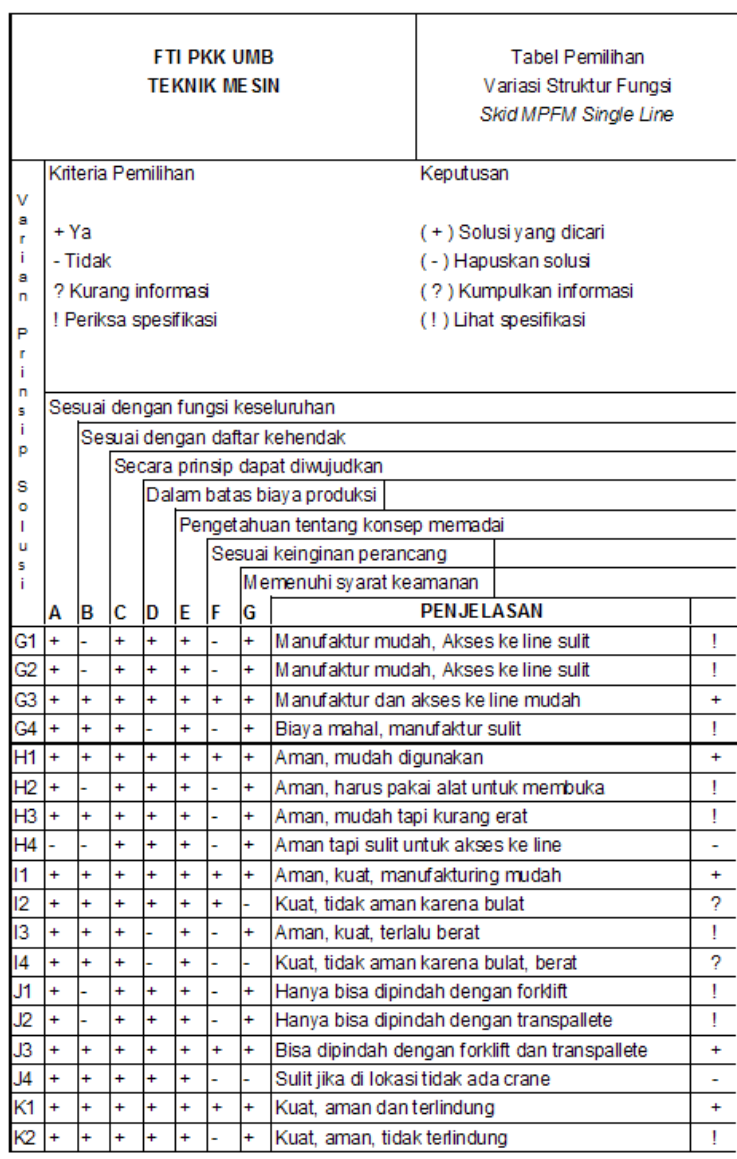

Tabel 4. Alternatif Jalur Variasi

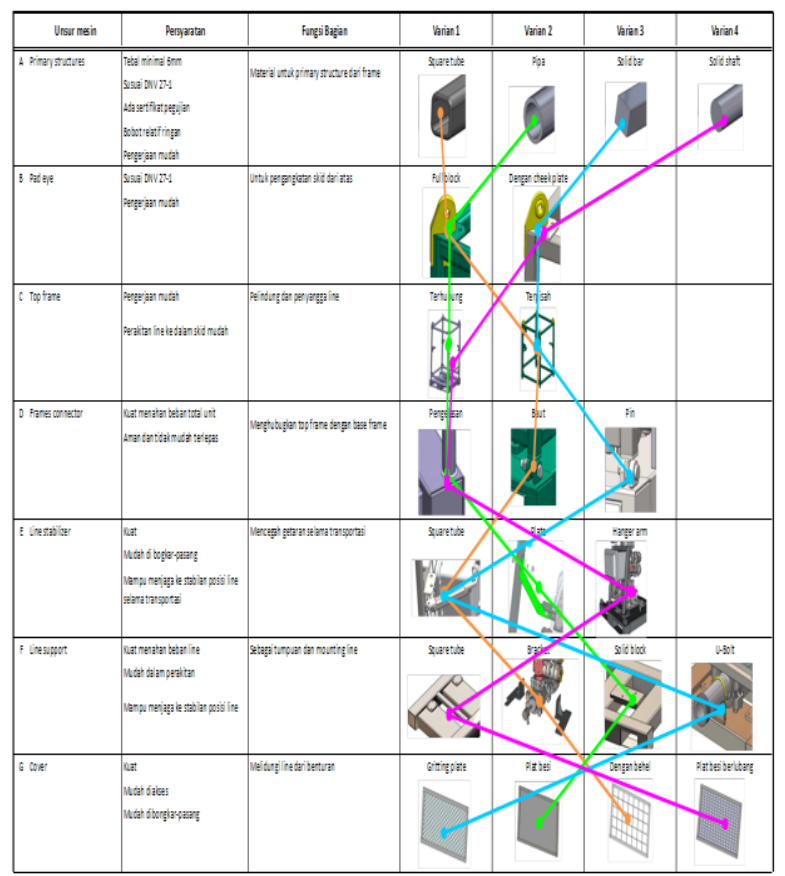

Dari tabel 3. tersebut dapat dikembangkan lagi menjadi alternatif jalur variasi prinsip solusi yang akan menghasilkan 4 varian rancangan (tabel 4.).

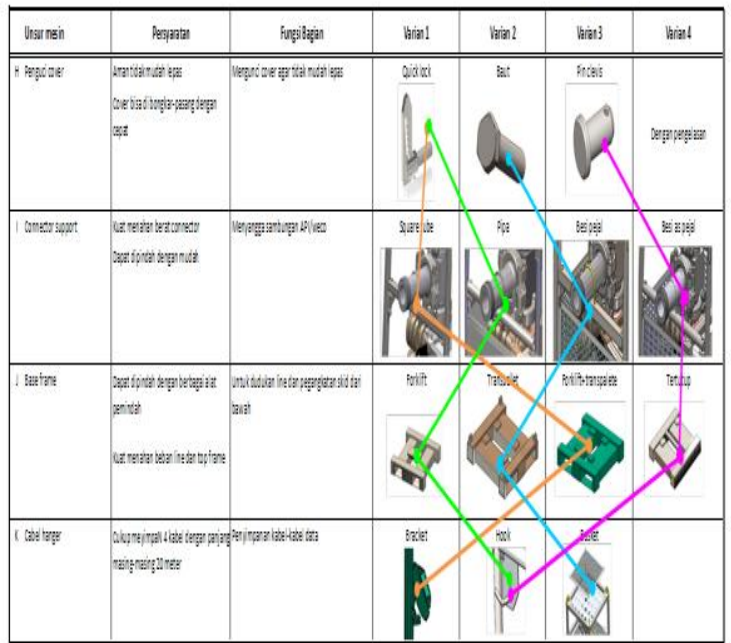

Kemudian jalur variasi prinsip solusi diatas diberikan penilaian sebagaimana yang diperlihatkan pada tabel-tabel berikut.

Tabel 5. Penilaian Variasi 1

\begin{tabular}{|c|c|c|c|c|c|}
\hline \multirow[t]{2}{*}{ No. } & \multirow[t]{2}{*}{ Kriteria } & Bobot & \multirow[t]{2}{*}{ Parameter } & $\begin{array}{c}\text { Nilai } \\
\text { Varian } \\
1\end{array}$ & $\begin{array}{l}\text { Sub } \\
\text { total }\end{array}$ \\
\hline & & (Wi) & & Vi & Wi.Vi \\
\hline 1 & Safery & 0,18 & $\begin{array}{l}\text { Tidak membahayakan } \\
\text { pengguna }\end{array}$ & 9 & 1,62 \\
\hline 2 & Indah dilihat & 0,05 & Kepuasan customer & 8 & 0,4 \\
\hline 3 & Mudah dirakit & 0,1 & $\begin{array}{l}\text { Kecepatan dan ketepatan } \\
\text { merakit }\end{array}$ & 9 & 0,9 \\
\hline 4 & Jumlah komponen & 0,07 & Jumlah komponen & 7 & 0,49 \\
\hline 5 & $\begin{array}{l}\text { Komponen } \\
\text { sederhana }\end{array}$ & 0,06 & Tingkat kerumitan komponen & 8 & 0,48 \\
\hline 6 & $\begin{array}{l}\text { Komponen mudah } \\
\text { didapat }\end{array}$ & 0,15 & Ketersediaan di pasar lokal & 8 & 1,2 \\
\hline 7 & $\begin{array}{l}\text { Ringkas dan tidak } \\
\text { berat }\end{array}$ & 0,2 & Faktor transportasi & 10 & 2 \\
\hline 8 & $\begin{array}{l}\text { Mudah dalam } \\
\text { perawatan }\end{array}$ & 0,05 & Biava per awatan & 8 & 0,4 \\
\hline 9 & $\begin{array}{l}\text { Toleransi bentuk } \\
\text { dan dimensi }\end{array}$ & 0,08 & Ketepatan ukuran dan bentuk & 8 & 0,64 \\
\hline 10 & $\begin{array}{l}\text { Komponen mudah } \\
\text { dibuat }\end{array}$ & 0,06 & Mudah dalam pengerjaan & 8 & 0,48 \\
\hline & & 1 & & 83 & 8,61 \\
\hline
\end{tabular}

Tabel 6. Penilaian Variasi 2 
Vol. I No.2 Juni 2018

http://joernal.umsb.ac.id/index.php/RANGTEKNIKJOURNAL

\begin{tabular}{|c|c|c|c|c|c|}
\hline \multirow[t]{2}{*}{ No. } & \multirow[t]{2}{*}{ Kriteria } & Bobot & \multirow[t]{2}{*}{ Parameter } & $\begin{array}{c}\text { Nilai } \\
\text { Varian } \\
2\end{array}$ & $\begin{array}{l}\text { Sub } \\
\text { total }\end{array}$ \\
\hline & & (Wi) & & $\mathrm{Vi}$ & Wi.Vi \\
\hline 1 & Safeny & 0,18 & $\begin{array}{l}\text { Tidak membahayakan } \\
\text { pengguna }\end{array}$ & 7 & 1,26 \\
\hline 2 & Indah dilihat & 0,05 & Kepuasan customer & 7 & 0,35 \\
\hline 3 & Mudah dirakit & 0,1 & $\begin{array}{l}\text { Kecepatan dan ketepatan } \\
\text { merakit }\end{array}$ & 7 & 0,7 \\
\hline 4 & Jumlah komponen & 0,07 & Jumlah komponen & 7 & 0,49 \\
\hline 5 & $\begin{array}{l}\text { Komponen } \\
\text { sederhana }\end{array}$ & 0,06 & Tingkat kerumitan komponen & 5 & 0,3 \\
\hline 6 & $\begin{array}{l}\text { Komponen mudah } \\
\text { didapat }\end{array}$ & 0,15 & Ketersediaan di pasar lokal & 8 & 1,2 \\
\hline 7 & $\begin{array}{l}\text { Ringkas dan tidak } \\
\text { berat }\end{array}$ & 0,2 & Faktor transportasi & 8 & 1,6 \\
\hline 8 & $\begin{array}{l}\text { Mudah dalam } \\
\text { perawatan }\end{array}$ & 0,05 & Biaya per awatan & 8 & 0,4 \\
\hline 9 & $\begin{array}{l}\text { Toleransi bentuk } \\
\text { dan dimensi }\end{array}$ & 0,08 & Ketepatan ukuran dan bentuk & 7 & 0,56 \\
\hline 10 & $\begin{array}{l}\text { Komponen mudah } \\
\text { dibuat }\end{array}$ & 0,06 & Mudah dalam pengerjaan & 6 & 0,36 \\
\hline & & 1 & & 70 & 7,22 \\
\hline
\end{tabular}

Tabel 7. Penilaian Variasi 3

\begin{tabular}{|c|c|c|c|c|c|}
\hline \multirow[t]{2}{*}{ No. } & \multirow[t]{2}{*}{ Kriteria } & Bobot & \multirow[t]{2}{*}{ Parameter } & $\begin{array}{c}\text { Nilai } \\
\text { Varian } \\
3\end{array}$ & $\begin{array}{l}\text { Sub } \\
\text { total }\end{array}$ \\
\hline & & (Wi) & & $\mathrm{Vi}_{\mathrm{i}}$ & Wi.Vi \\
\hline 1 & Safety & 0,18 & $\begin{array}{l}\text { Tidak membahayakan } \\
\text { pengguna }\end{array}$ & 9 & 1,62 \\
\hline 2 & Indah dilihat & 0,05 & Kepuasan customer & 6 & 0,3 \\
\hline 3 & Mudah dirakit & 0,1 & $\begin{array}{l}\text { Kecepatan dan ketepatan } \\
\text { merakit }\end{array}$ & 9 & 0,9 \\
\hline 4 & Jumlah komponen & 0,07 & Jumlah komponen & 5 & 0,35 \\
\hline 5 & $\begin{array}{l}\text { Komponen } \\
\text { sederhana }\end{array}$ & 0,06 & Tingkat kerumitan komponen & 7 & 0,42 \\
\hline 6 & $\begin{array}{l}\text { Komponen mudah } \\
\text { didapat }\end{array}$ & 0,15 & Ketersediaan di pasar lokal & 8 & 1,2 \\
\hline 7 & $\begin{array}{l}\text { Ringkas dan tidak } \\
\text { berat }\end{array}$ & 0,2 & Faktor transportasi & 6 & 1,2 \\
\hline 8 & $\begin{array}{l}\text { Mudah dalam } \\
\text { perawatan }\end{array}$ & 0,05 & Biaya per awatan & 7 & 0,35 \\
\hline 9 & $\begin{array}{l}\text { Toleransi bentuk } \\
\text { dan dimensi }\end{array}$ & 0,08 & Ketepatan ukuran dan bentuk & 7 & 0,56 \\
\hline 10 & $\begin{array}{l}\text { Komponen mudah } \\
\text { dibuat }\end{array}$ & 0,06 & Mudah dalam pengerjaan & 8 & 0,48 \\
\hline & & 1 & & 72 & 7,38 \\
\hline
\end{tabular}

Tabel 8. Penilaian Variasi 4

\begin{tabular}{|c|c|c|c|c|c|}
\hline \multirow[t]{2}{*}{ No. } & \multirow[t]{2}{*}{ Kriteria } & Bobot & \multirow[t]{2}{*}{ Parameter } & $\begin{array}{c}\text { Nilai } \\
\text { Varian } \\
3\end{array}$ & $\begin{array}{l}\text { Sub } \\
\text { total }\end{array}$ \\
\hline & & (Wi) & & Vi & Wi.Vi \\
\hline 1 & Safety & 0,18 & $\begin{array}{l}\text { Tidak membahayakan } \\
\text { pengguna }\end{array}$ & 7 & 1,26 \\
\hline 2 & Indah dilihat & 0,05 & Kepuasan customer & 5 & 0,25 \\
\hline 3 & Mudah dirakit & 0,1 & $\begin{array}{l}\text { Kecepatan dan ketepatan } \\
\text { merakit }\end{array}$ & 7 & 0,7 \\
\hline 4 & Jumlah komponen & 0,07 & Jumlah komponen & 6 & 0,42 \\
\hline 5 & $\begin{array}{l}\text { Komponen } \\
\text { sederhana }\end{array}$ & 0,06 & Tingkat kerumitan komponen & 6 & 0,36 \\
\hline 6 & $\begin{array}{l}\text { Komponen mudah } \\
\text { didapat }\end{array}$ & 0,15 & Ketersediaan di pasar lokal & 8 & 1,2 \\
\hline 7 & $\begin{array}{l}\text { Ringkas dan tidak } \\
\text { berat }\end{array}$ & 0,2 & Faktor transportasi & 6 & 1,2 \\
\hline 8 & $\begin{array}{l}\text { Mudah dalam } \\
\text { perawatan }\end{array}$ & 0,05 & Biaya per awatan & 7 & 0,35 \\
\hline 9 & $\begin{array}{l}\text { Toleransi bentuk } \\
\text { dan dimensi }\end{array}$ & 0,08 & Ketepatan ukuran dan bentuk & 7 & 0,56 \\
\hline 10 & $\begin{array}{l}\text { Komponen mudah } \\
\text { dibuat }\end{array}$ & 0,06 & Mudah dalam pengerjaan & 7 & 0,42 \\
\hline & & 1 & & 66 & 6,72 \\
\hline
\end{tabular}

Setelah mendapatkan nilai dari evaluasi setiap prinsip solusi maka dipilihlah rancangan dengan nilai tertinggi pada tabel berikut:

Tabel 9. Kesimpulan Nilai Evaluasi per Varian

\begin{tabular}{|r|l|r|}
\hline No. & Penilaian evaluasi & Nilai \\
\hline \hline 1 & Varian 1 & 8,61 \\
\hline 2 & Varian 2 & 7,22 \\
\hline 3 & Varian 3 & 7,38 \\
\hline 4 & Varian 4 & 6,72 \\
\hline
\end{tabular}

Dari tabel di atas maka yang dipilih adalah varian 1 dengan nilai tertinggi karena varian ini lebih sesuai dengan permintaan dan spesifikasi yang diinginkan customer dan perancang. Varian ini memiliki kekuatan yang cukup untuk menerima beban kerja, bobot tidak terlalu berat dan mudah dalam proses permesinan karena berupa tubing persegi empat, serta peralatan dan asesoris yang sederhana dan mudah dioperasikan.

Varian 4 merupakan varian dengan nilai terkecil dikarenakan bentuk primary structure yang bulat dan pejal sehingga sangat sulit dalam proses permesinan serta bobot yang relatif berat. Karena bentuknya yang 
pejal sehingga sambungan yang termudah adalah sambungan pengelasan yang mengakibatkan sulitnya perakitan dan akses untuk perawatan unit.

\section{SIMPULAN DAN SARAN}

Dari metode VDI 2221 telah dapat dihasilkan rancangan suatu produk generasi terbaru dengan dimensi yang kecil, bobot yang ringan tapi tetap kuat menahan beban lebih dari $800 \mathrm{~kg}$ dan kokoh menjaga line $M P F M$ dari benturan benda lain.

Rancangan ini didapatkan melalui penjabaran metode VDI 2221 dengan memilih varian 1 karena mempunyai nilai tertinggi dari hasil penilaian varian prinsip solusi. Keunggulan varian ini terletak pada kesesuaian antara permintaan dan spesifikasi yang telah ditentukan, cukup kuat untuk menerima beban kerja, bobot yang relatif ringan, mudah dalam proses permesinan karena berupa tubing persegi empat, peralatan dan asesoris yang sederhana memudahkan perakitan, pengoperasian dan perawatannya.

Untuk proses perancangan dengan schedule yang singkat dan ketat, pembuatan variasi yang detail serta gambar produk per variasi suatu waktu akan menjadi beban dan membuang banyak waktu dan pikiran. Dalam hal ini pembuatan tabel prinsip solusi bisa disederhanakan dengan sketsa tangan sederhana atau sekedar deskripsi tulisan.

\section{DAFTAR PUSTAKA}

Budynas, Richard G., and J. Keith Nissbet. 2008. Shigley's Mechanical Engineering Design 8th Edition in S.I Unit. New York : McGraw-Hill.

Mott, Robert L. 2004. Machine Elements in Mechanical Design 4rd Edition. New Jersey : Pearson Prentice Hall.

Singer, Ferdinand L., and Andrew Pytel. 1985. Kekuatan Bahan edisi Ketiga (Teori Kokoh - Strength of Material). Jakarta : Erlangga.

Ugural, Ansel C. 2003.Mechanical Design An Integrated Approach. Singapore : The McGraw-Hill Companies. Inc.

Maraven, 1997. "A Multiphase Flow Meter New Technology for Well Testing", Ingenios, vol. 26.

Mechanical Standard Components. 2007. Misumi Corporation
Mofunlewi, Samuel S., Joseph A. Ajienka and D. Appah, 2008. "Determination of Multiphase Flow Meter Reliability and Development of Correction Charts for the Prediction of Oilfield Fluid Flow Rates", Leonardo Journal of Sciences, vol.12 : 1583 - 0233 .

Ruli Nutranta. 2008. Modul Perancangan Produk. Jakarta : Universitas Mercu Buana.

$\begin{array}{lr}\text { Fakultas Teknik UMSB } & \text { ISSN 2599-2081 } \\ \text { EISSN 2599-2090 }\end{array}$

